\title{
Analisis Strategi E-Marketing Dalam Upaya Peningkatan Penjualan Travel Agent Online mybaliwisata.com
}

\author{
Fitria Pebri Evariyanti ${ }^{1 *}$, Ni Made Estiyanti ${ }^{2 *}$, Sephy Lavianto ${ }^{3 *}$ \\ * Sistem Informasi Akuntansi, STMIK Primakara Denpasar \\ fitriapebri20@gmail.com ${ }^{1}$, estiyanti@primakara.ac.id ${ }^{2}, \underline{\text { sephylavianto59@gmail.com }}{ }^{3}$
}

\begin{tabular}{l}
\hline Article Info \\
\hline Article history: \\
Received 04-03-2019 \\
Revised 02-05-2019 \\
Accepted 03-05-2019 \\
\hline
\end{tabular}

\section{Keyword:}

online travel agent, e-marketing strategy,

Break Event Point (BEP) analysis, mybaliwisata.com.

\begin{abstract}
Every year the graph of foreign and domestic tourist arrivals to Bali continues to increase. This is a great opportunity to increase tourist destination visits to Bali. The role of technology will answer the problems that exist in this era of globalization by using computerized systems, so that the use of information technology helps effectiveness and efficiency in working on information system processes. After analyzing the Business Model Canvas (BMC) and E-marketing Business data using social media, the results obtained were an increase in sales of mybaliwisata.com online travel agents in increasing sales turnover. This study uses the Break Event Point (BEP) analysis method to calculate the valuation of mybaliwisata.com online travel agent company, so that optimization of the increase in mybaliwisata.com Travel Agent Online sales can be done well.
\end{abstract}

Copyright (C) 2019 Journal of Applied Informatics and Computing. All rights reserved.

\section{Pendahuluan}

Indonesia merupakan negara beraneka ragam adat suku dan budaya. Indonesia terdiri dari 34 provinsi yang masingmasing memiliki ciri khas budaya. Bali terdiri atas 8 (delapan) Kabupaten + (plus) 1 (satu) Kota Denpasar yang tiap kabupatennya pun memiliki khas budaya yang beraneka ragam, serta unik untuk dapat mempelajarinya lebih dalam. Berdasarkan data Badan Pusat Statistik Provinsi Bali mengenai data kunjungan wisatawan asing langsung ke bali menyatakan bahwa jumlah kedatangan langsung pada Januari-November 2017 adalah 4.683 .582 wisatawan dan jumlah kedatangan langsung pada Januari-November 2016 adalah 3.957.193 wisatawan. Sehingga Jumlah kedatangan asing langsung pada tahun 2017 meningkat 18,36\% dibandingkan dengan 2016. Setiap tahunnya grafik kunjungan wisatawan mancanegara dan domistik ke Bali terus meningkat. Hal ini menjadi peluang besar untuk meningkatkan rasa destinasi wisatawan yang berbeda saat ke Bali.

Penelitian sebelumnya yang telah dilakukan Fitria pada tahun 2016 telah mendapatkan hasil survei kunjungan wisatawan mancanegara dan domestik ke Bali sebagai berikut [2].
TABEL I

HASIL SURVEI KUNJUNGAN WiSATAWAN MANCANEGARA DAN DOMESTIK KE BALI

\begin{tabular}{|c|c|c|c|c|c|c|}
\hline \multicolumn{7}{|c|}{ Wisatawan Mancanegara } \\
\hline Variabel & Keterangan & Persen & Keterangan & Persen & Keterangan & Persen \\
\hline $\begin{array}{l}\text { Pengetahuan } \\
\text { Mengenai } \\
\text { Objek } \\
\text { Wisata } \\
\end{array}$ & $\begin{array}{l}\text { Keseluruhan } \\
\text { Objek Wisata }\end{array}$ & $50 \%$ & $\begin{array}{c}\text { Beberapa Objek } \\
\text { Wisata }\end{array}$ & \multicolumn{3}{|c|}{$\mathbf{5 0 \%}$} \\
\hline $\begin{array}{l}\text { Ketertarikan } \\
\text { Mengenai } \\
\text { Objek } \\
\text { Wisata }\end{array}$ & Wisata Alam & $57 \%$ & Wisata Budaya & $14 \%$ & Wisata Kuliner & $29 \%$ \\
\hline $\begin{array}{l}\text { Ketertarikan } \\
\text { Mengenai } \\
\text { Kegiatan } \\
\text { Wisata } \\
\end{array}$ & $\begin{array}{c}\text { Kegiatan } \\
\text { Sosial }\end{array}$ & $30 \%$ & $\begin{array}{c}\text { Kegiatan Tradisi } \\
\text { Budaya }\end{array}$ & $40 \%$ & Kegiatan Spiritual & $\mathbf{3 0} \%$ \\
\hline \multicolumn{7}{|c|}{ Wisatawan Domestik } \\
\hline Variabel & Keterangan & Persen & Keterangan & Persen & Keterangan & Persen \\
\hline $\begin{array}{l}\text { Pengetahuan } \\
\text { Mengenai } \\
\text { Objek } \\
\text { Wisata }\end{array}$ & $\begin{array}{c}\text { Beberapa } \\
\text { Objek Wisata }\end{array}$ & $87,6 \%$ & $\begin{array}{l}\text { Keseluruhan } \\
\text { Objek Wisata }\end{array}$ & \multicolumn{3}{|c|}{$13,3 \%$} \\
\hline $\begin{array}{l}\text { Ketertarikan } \\
\text { Mengenai } \\
\text { Objek } \\
\text { Wisata }\end{array}$ & Wisata Alam & $52 \%$ & Wisata Budaya & $24 \%$ & Wisata Spiritual & $24 \%$ \\
\hline $\begin{array}{l}\text { Ketertarikan } \\
\text { Mengenai } \\
\text { Kegiatan } \\
\text { Wisata } \\
\end{array}$ & $\begin{array}{c}\text { Kegiatan } \\
\text { Sosial }\end{array}$ & $35 \%$ & $\begin{array}{l}\text { Kegiatan Tradisi } \\
\text { Budaya }\end{array}$ & $55 \%$ & Kegiatan Spiritual & $10 \%$ \\
\hline
\end{tabular}

Hal ini membuktikan bahwa wisatawan mancanegara dan domestik sangat membutuhkan sarana untuk membantu mereka mempelajari budaya yang ada di Bali, dan sangat tertarik untuk mempelajarinya lebih dalam. Namun, Indonesia masih belum memaksimalkan pemanfaatan dari teknologi informasi tersebut dalam pengembangan bisnis 
dengan ekspansi yang luas, karena hanya beberapa perusahaan saja yang mampu menggunakan teknologi informasi secara maksimal seperti Gojek, Bukalapak, Traveloka, PT Telkom, PT Sigma dan lainnya (Antaranews, 2016), padahal teknologi informasi sangat diperlukan untuk penyebaran sistem informasi lebih cepat. Untuk itu peneliti membuat sebuah sistem informasi travel agent online mybaliwisata.com adalah konten yang sama dengan langitbudaya.com untuk mempermudah wisatawan untuk adventure di Bali.

Hasil jurnal yang dilakukan Meyliana tahun 2011 yang berjudul Analisis Strategi E-Marketing Dan Implementasinya Pada Rental Company menyimpulkan bahwa kegiatan pemasaran dengan bantuan teknologi informasi, e-marketing, dilakukan untuk meningkatkan image perusahaan [8]. Setelah dianalisis, strategi $e$ marketing ini akan diimplementasikan pada perusahaan yang memiliki jenis usaha penyewaan. Jadi, dengan adanya strategi e-marketing dalam penjualan travel agent online mybaliwisata.com diharapkan dapat meningkatkan omset penjualan serta dengan analisis penjualan yang baik di travel agent online mybaliwisata.com.

\section{METODE}

Metode yang dilakukan untuk dapat menganalisis strategi e-marketing dalam upaya peningkatan penjualan travel agent online mybaliwisata.com adalah melakukan perancangan penelitian seperti gambar dibawah ini.

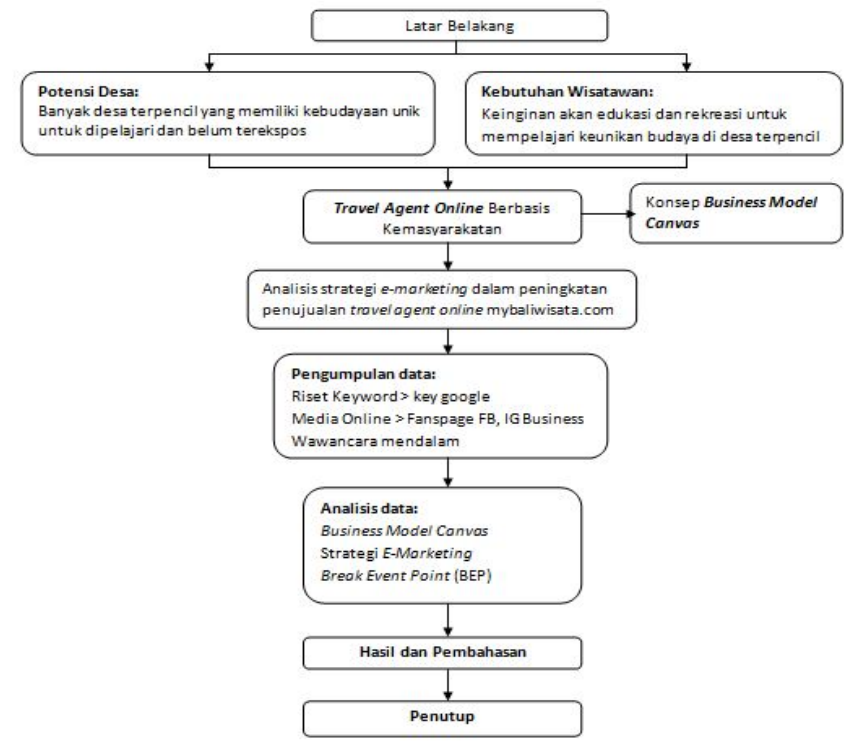

Gambar 1. Pemecahan Masalah Peneliti

Setelah mengetahui latar belakang potensi desa dan kebutuhan wisatawan yang diharapkan saat berlibur di Bali, penulis membentuk sebuah bisnis digital travel agent online berbasis kemasyarakatan dengan konsep Business Model Canvas (BMC). Selanjutnya dari konsep BMC tersebut kita lakukan analisis strategi e-marketing dalam peningkatan penjualan travel agent online mybaliwisata.com. Pengumpulan data yang dilakukan meliputi; pencarian riset keyword dengan menggunakan key googles untuk menciptakan sebuah website yang bernama mybaliwisata.com dan nantinya akan dianalisis strategi emarketing dalam peningkatan penjualan travel agent online, kemudian melakukan observasi selama 5 bulan melalui media social berupa fanspage facebook dari akun mybaliwisata.com dan Instagram business dari akun mybaliwisata.com untuk mengetahui peningkatan strategi emarketing yang dilakukan mybaliwisata.com, dan terakhir melalukan wawancara mendalam dengan pihak-pihak terkait yang berperan untuk memperkuat hasil analisis dari strategi e-marketing dalam peningkatan penjualan travel agent online mybaliwisata.com.

Setelah data-data untuk dianalisis terkumpul, selanjutnya penulis melakukan kajian analisis data dengan beberapa analisis yang meliputi; Analisis Bisnis Model Canvas untuk mengetahui seberapa layak bisnis ini untuk dikembangkan, selanjutnya melakukan analisis strategi e-marketing melalui media social berupa facebook dan instagram, hasil dari analisis beberapa strategi e-marketing dengan media facebook dan instagram penulis lakukan analisis break event point (BEP) untuk mengetahui pertumbuhan potensi bisnis yang dimiliki oleh mybaliwsata.com. Setelah mendapatkan nilai BEP penjualan bisnis mybaliwisata.com, penulis menggunakan salah satu metode untuk menghitung prospek pertumbuhan suatu instrumen investasi dalam beberapa waktu ke depan yaitu Discounted Cash Flow atau biasa disingkat DCF. Disebut 'discounted cash flow' atau 'arus kas yang terdiskon', karena cara menghitungnya adalah dengan meng-estimasi arus dana dimasa mendatang untuk kemudian di-cut dan menghasilkan nilai dana tersebut pada masa kini. Sehingga dapat ditarik kesimpulan yang dapat menghasilkan rekomendasi terhadap penelitian yang dibuat guna mendapatkan jawaban dalam menganalisis strategi $e$ marketing dalam peningkatan penjualan travel agent online mybaliwisata.com.

Jenis dan sumber data yang digunakan meliputi; data kualitatif untuk mengetahui potensi wisata yang belum terekspos di Bali dan literature dalam analisis strategi $e$ marketing dalam peningkatkan penjualan travel agent online mybaliwisata.com, data kuantitatif untuk mengetahui data desa-desa wisata yang belum terekspos di Bali dan data-data potensi wisata yang belum terkenal di Bali, selanjutnya sumber primer diperoleh dari hasil wawancara dengan para responden/informan dalam penelitian ini, dan sumber sekunder diperoleh dari buku-buku literatur, jurnal ilmiah, dan hasil penelitian terdahulu.

Penentuan informan atau responden dalam penelitian ini ditentukan berdasarkan teknik Random Sampling. Menurut Cholid dalam bukunya pada tahun 1997 yaitu teknik Random Sampling adalah teknik pengambilan sampel secara rambang atau acak yaitu pengambilan sampel tanpa pilih- 
pilih atau tanpa pandang bulu, di dasarkan atas prinsipprinsip matematis yang telah diuji dalam praktek [3] Dengan Teknik pengumpulan data berupa observasi, wawancara mendalam, dan studi kepustakaan. Penelitian dan pengerjaan sistem dilakukan di Bali tepatnya daerah Denpasar dan beberapa kawasan untuk melakukan kegiatan edukasi travel dari mulai Bulan April sampai dengan Agustus 2018.

\section{HASIL}

Hasil penelitian yang diperoleh penulis diantaranya; konsep bisnis digital dengan Business Model Canvas (BMC) yang merupakan alat strategi untuk mendeskripsikan sebuah model bisnis dan menggambarkan dasar pemikiran tentang gambaran detail sebuah bisnis dengan pemaparan yang singkat. Menurut Kurniawan pada tahun 2012 menyatakan Bagan-bagan dari Business Model Canvas (BMC) meliputi; Key Activities, Key Resources, Partner Network, Value Propositions, Customer Segments, Channel, Customer Relationship, Cost Structure, dan Revenue Stream[7] sebagai berikut:

TABEL II

BUSINESS MODEL CANVAS MYBALIWISATA.COM

\begin{tabular}{|c|c|c|c|c|}
\hline \multirow[t]{2}{*}{$\begin{array}{ll}\text { Key Patners: } \\
\text { 1. Desa Wisata } \\
\text { 2. Objek } \\
\text { Wisata } \\
\text { 3. Driver } \\
\text { Guide } \\
\text { 4. Restaurant } \\
\text { 5. } \text { Hotel }\end{array}$} & $\begin{array}{l}\text { KeyActivities: } \\
\text { 1. Trip budaya dan } \\
\text { wisata halal di } \\
\text { Bali. } \\
\text { 2. Eksplore desa } \\
\text { wisata. }\end{array}$ & \multirow[t]{2}{*}{$\begin{array}{|ll|}\text { Value } \\
\text { Proposition: } \\
\text { 1. } & \text { Mengenal } \\
& \text { Bali dengan } \\
& \text { konsep Tri } \\
& \text { Hita Karana } \\
\text { 2. } & \text { Private Trip }\end{array}$} & $\begin{array}{l}\text { Customer } \\
\text { Relationship: } \\
\text { 1. Member } \\
\text { Card } \\
\text { 2. Promo Trip }\end{array}$ & \multirow[t]{2}{*}{$\begin{array}{l}\text { Customer Segment } \\
\text { 1. Domestik } \\
\text { 2. Mancanegara }\end{array}$} \\
\hline & $\begin{array}{ll}\text { Key Resources: } \\
\text { 1. } & \text { Programmer } \\
\text { 2. } & \text { Designer } \\
\text { 3. } & \text { Marketing } \\
\text { 4. } & \text { Akunting }\end{array}$ & & $\begin{array}{l}\text { Channels: } \\
\text { 1. Website } \\
\text { 2. Sosial Media } \\
\text { (FB dan IG) } \\
\text { 3. Youtobe } \\
\text { 4. Whatsapp }\end{array}$ & \\
\hline \multicolumn{2}{|c|}{$\begin{array}{l}\text { CostStructure: } \\
\text { 1. Mantenance Program } \\
\text { 2. Operasional Trip } \\
\text { 3. } \\
\text { E-marketing }\end{array}$} & \multicolumn{2}{|c|}{$\begin{array}{l}\text { Revenue Streams: } \\
\text { 1. Iklan } \\
\text { 2. Customer } \\
\text { 3. Investor }\end{array}$} & \\
\hline
\end{tabular}

Konsep bisnis digital yang bergerak dibidang travel agent online dimana mybaliwisata.com sebagai penghubung bagi wisatawan dengan desa wisata yang berbasis kemasyarakatan disetujui oleh Dinas Pariwisata Provinsi Bali dimana beberapa desa yang tercantum dalam daftar Desa Wisata Sasaran Program Aksi Bali Mandara Jilid II Dari Tahun 2013-2018 dari Dinas Pariwisata Provinsi Bali tersebut telah ditinjau langsung oleh penulis dan telah melaksanakan perjanjian kerjasama bersama mybaliwisata.com, dimana pihak mybaliwisata.com selaku penghubung antara desa wisata dengan wisatawan serta bertindak sebagai promosi online bagi desa wisata itu sendiri.

Beberapa penelitian terdahulu seperti; Penelitian Gian pada tahun 2015 berjudul "Sistem Informasi Pelayanan Jasa Tour Dan Travel Berbasis Website Electronic Commerce (Studi Kasus Ninetours Indonesia)" menyimpulkan bahwa Sistem informasi pelayanan jasa tour dan travel berbasis website electronic commerce yang dirancang secara terintegrasi untuk membantu perusahaan dalam perbaikan proses pemesanan, memperluas pemasaran dan meningkatkan loyalitas pelanggan [4],[9]. Penelitian ini juga memiliki kesamaan tujuan dari penelitian ini yaitu perancangan sistem berbasis website dilakukan guna membantu perusahaan nantinya dalam perbaikan proses pemesanan, memperluas pamasaan dan meningkatkan peyalitas pelanggan.

Hasil penelitian Asti, dkk pada tahun 2015 yang berjudul Pengembangan Website Magazine Jatengtravelguide.Com (Divisi Reporter, Desainer Grafis Dan News Editor) menyimpukan bahwa Pengembangan website Jatengtravelguide.com telah berhasil mendapatkan pengunjung 9123 viewers dari target goals yang hanya 6000 viewers [1]. Selama 2 bulan itu pula website telah berhasil membuat dan mengunggah 60 artikel ke dalam website. Website Jatengtravelguide.com juga mendapatkan 18 komentar yang artinya audiens sudah terlibat lebih jauh pada website ini. Hal tersebut yang akan diimplementasikan dalam penelitian ini dengan pengembangan website travel agent guna menghasilkan viewers yang nantinya dapat meningkatkan hasil penjualan pada travel agent.

Mybaliwisata.com melakukan strategi e-marketing dengan media online berupa Fan Page Facebook dan Instagram. Menurut informasi mutesix.com yang diakses tahun 2016 yaitu pemanfaatan facebook ads bertujuan untuk meningkatkan jumlah calon konsumen yang mengingat merek sebuah produk setelah produk tersebut diiklankan. Estimasi calon konsumen dapat mengingat sebuah merek adalah dalam waktu kurang lebih 2 hari setelah mereka melihat kampanye merek tersebut diluncurkan di facebook [6].

Berdasarkan data yang diungkapkan oleh Brand Development Lead APAC Instagram, Paul Webster, total pengguna Instagram di seluruh dunia mencapai 400 juta orang. Sebanyak 75 persen di antaranya merupakan pengguna Instagram yang berada di luar Amerika Serikat. Dari keseluruhan pengguna tersebut, 22 juta merupakan pengguna dari Indonesia dan rata-rata pengguna Instagram menghabiskan 21 menit per hari untuk membuka aplikasi ini [5].

Hasil selama 5 bulan penelitian dengan media sosial yaitu Fan Page Facebook telah memiliki total pengikut 496, total menyukai halaman 496, trafik jangkauan saat promosi iklan dengan facebook ads mencapai 97.873 orang. Sedangkan untuk Instagram telah memiliki total pengikut 10.000 , jangkuan jelajah saat promosi iklan mencapai 600 orang dengan impresi mencapai 4.573 orang.

Salah satu contoh data promosi pada bagian facebook ads yang terintegrasi dengan Instagram pula memperoleh hasil sebagai berikut: 


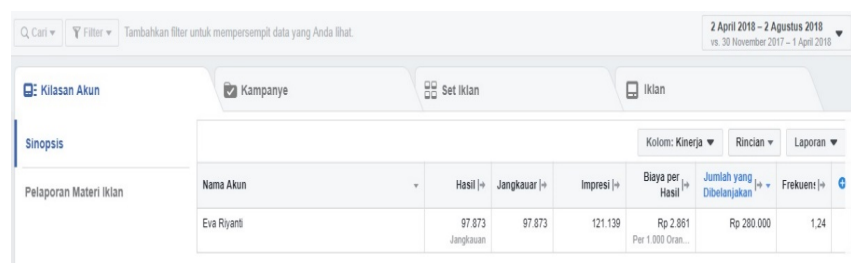

Gambar 2. Akun Iklan

Pada menu pengelola iklan ada beberapa bagian yang dapat kita analisis diantaranya; kilasan akun, kampanye, set iklan, dan iklan. Pada sub laporan materi terdapat nama akun dimana Eva Riyanti sebagai akun personal yang mengelola halaman@mybaliwisata1, hasil yang diperloreh dengan rincian; 97.873 jangkauan orang, impresi sebanyak 121.139, biaya perhasil 1.000 orang senilai 2.861, jumlah yang dibelanjakan Rp. 280.000, dan frekuensi 1,24.

Kemudahan pengunjung untuk langsung menghubungi kontak mybaliwisata.com, akun media social facebook dan Instagram dilengkapi fitur klik kontak yang langsung terdirect pada whatsapp bisnis mybaliwisata.com.

Penggunaan media sosial sebagai startegi e-marketing pada mybaliwisata.com meliputi; Fan Page Facebook Facebook, instagram business, dan Whatsapp Business. Beberapa media sosial ini merupakan salah satu strategi $e$ marketing untuk meningkatkan trafik website mybaliwisata.com dan mempermudah menjangkau pasar website mybaliwisata.com di kancah Nasional hingga Internasional. Berikut hasil trafik website mybaliwisata.com selama 5 bulan melakukan analisis strategi e-marketing melalui media sosial sebagai berikut.

TABEL III

Trafik Pengunjung Pada CPANEL

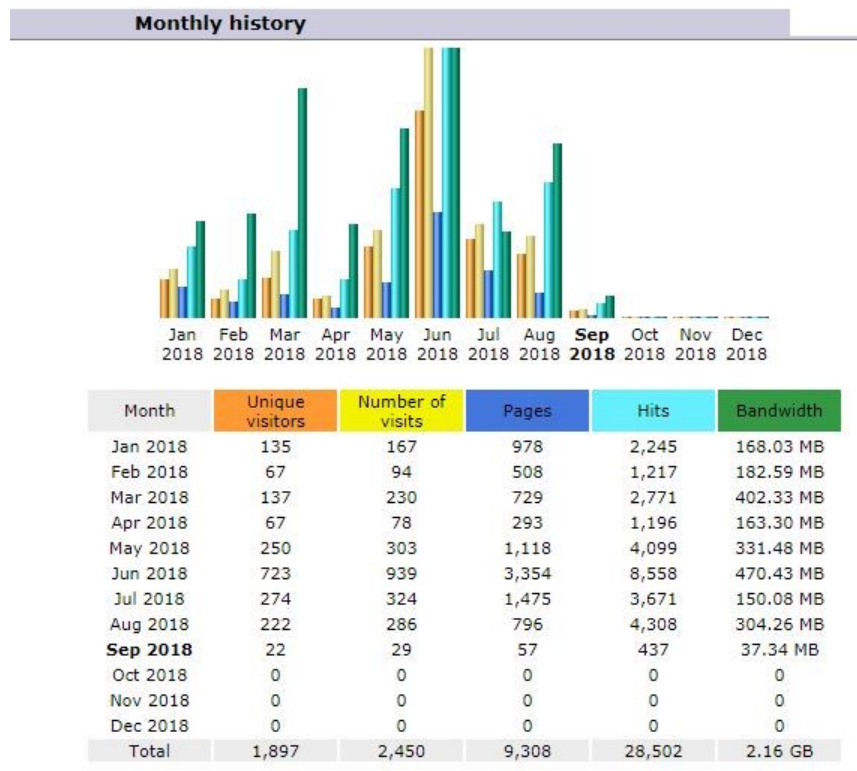

Trafik pengunjung website mybaliwisata.com dapat dilihat pada Cpanel. Cpanel merupakan web hosting control panel yang paling populer di dunia. Fasilitas ini memudahkan pemilik account hosting untuk mengatur seluruh fasilitas web hosting miliknya yaitu salah satunya trafik pengunjung yang mengunjungi website mybaliwisata.com.

Penggunaan strategi e-marketing menggunakan media sosial dilakukan oleh peneliti selama 5 bulan dan dimulai pada bulan April 2018 sampai bulan Agustus 2018. Terlihat trafik mengalami peningkatan pada bulan Juni 2018 dimana pengunjung pengguna yang unik mencapai 732, jumlah kunjungan mencapai 939, dan jumlah halaman yang dikunjungi sebanyak 3.354. Hal ini membuktikan bahwa media promosi pada media sosial facebook dapat menarik jangkauan kepada pengunjung, sehingga trafik pengunjung yang melihat halaman mybaliwisata.com mencapai ribuan.

\section{PEMBAHASAN}

Setelah menganalisis strategi e-marketing untuk meningkatkan penjualan travel agent online mybaliwisata.com, selanjutnya menganalisis bagaimana hasil data dari penjualan travel agent online mybaliwisata.com setelah mengimplementasikan strategi $e$ marketing yang dilakukan secara bersamaan selama 5 (lima) bulan tersebut. Berikut kondisi grafik pertumbuhan bisnis mybaliwisata.com selama penelitian dari bulan April sampai Agustus 2018.

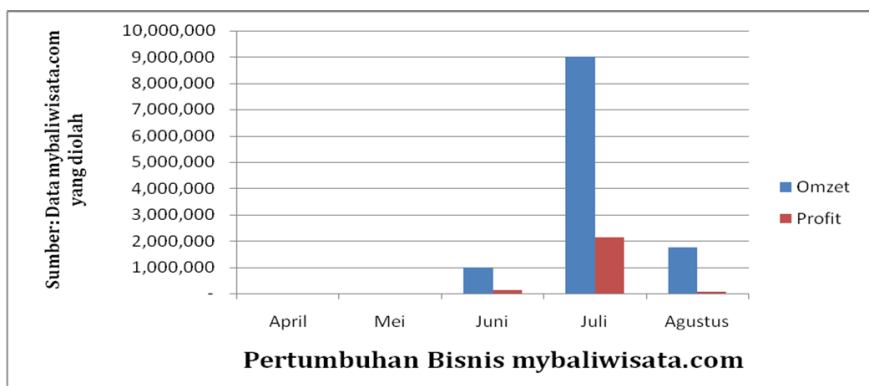

Gambar 3. Pertumbuhan Bisnis mybaliwisata.com

Dalam grafik tersebut terlihat pada bulan April dan Mei 2018 belum terjadi transaksi atau pendapatan dari mybaliwisata.com. Bulan April juga mybaliwisata.com memulai menggunakan media sosial dengan Facebook, Instagram, dan Whatsapp Businesss. Pada bulan Juni 2018, penulis menggunakan Facebook Ads untuk meningkatkan trafik di media sosial dan akun resmi website mybaliwisata.com. Pada bulan yang sama, mybaliwisata.com mendapatkan tamu dari Pasuruan paket tour Bedugul dan Jimbaran, sehingga terlihat hasil dari trafik pengunjung website meningkat dan dapat menarik tamu untuk menggunakan paket tour mybaliwisata.com dengan 
omset senilai $\mathrm{Rp} 1.000 .000$ dengan profit $\mathrm{Rp}$ 125.000. Di bulan Juli 2018 terlihat omset mybaliwisata.com mencapai Rp 9.000.000 dengan profit sebesar Rp 2.125.000. Di bulan Agustus 2018 terjadi pendapatan juga sebesar omset mencapai Rp 1.750.000 dengan profit sebesar Rp 75.000.

Dari hasil grafik pertumbuhan bisnis mybaliwisata.com dapat disimpulkan bahwa dengan adanya strategi $e$ marketing dengan media sosial akan memberi dampak dalam peningkatan terhadap pertumbuhan bisnis mybaliwisata.com. Media promosi yang ditawarkan media sosial memberi data yang valid dan sangat dibutuhkan bagi perkembangan pembisnis untuk mengetahui target pasar yang dituju dan mempercepat jangkauan pasar yang diinginkan. Dari hasil grafik tersebut, penulis dapat melakukan analisis pertumbuhan potensi bisnis yang dimiliki oleh mybaliwsata.com dengan metode BEP (Break Even Point). Penelitian Ponomban pada tahun 2013 menyatakan Break even point (titik impas) adalah suatu keadaan dimana sebuah perusahaan tidak memperoleh keuntungan dan juga tidak mengalami keruagian dari kegiatan operasinya, karena hasil penjualan yang diperoleh perusahaan sama besarnya dengan total biaya yang dikeluarkan perusahaan [10].

\section{Penjelasan:}

Kapasitas target penjualan 108 kali trip dalam 1 (satu) tahun, dimana mybaliwisata.com dengan perkiraan 9 (sembilan) paket dalam 1 (bulan) dikali 12 bulan, dengan ketentuan jumlah wisatawaan minimal 6 wisatawan $\times 108$ kali trip $=$ 648 wisatawan, dimana harga jual perorang diperkirakan Rp. $500.000,-$ / pack.

Sehingga total penjualan 648 wisatawan dapat mencapai Rp. 324.000.000,-

Total biaya tetap sebesar Rp. 48.000.000,- dan total biaya variabel sebesar Rp. 258.000,- /pack

Perincian masing-masing biaya adalah sebagai berikut:

\section{Fixed Cost}

$\begin{array}{lll}\text { E-marketing } & & \text { : Rp. } 15.600 .000,- \\ \text { Sewa } & & \text { : Rp. } 12.000 .000,- \\ \text { Internet } & & \text { : Rp. } 6.000 .000,- \\ \text { Transport } & & \text { : Rp. } 4.800 .000,- \\ \text { Gaji } & & \text { : Rp. } 9.600 .000,- \\ \text { TOTAL FC } & \text { : Rp. 48.000.000,- }\end{array}$

\section{Variable Cost}

$\begin{array}{ll}\text { Sewa Mobil } & \text { : Rp. } 450.000,- \\ \text { Guide } & \text { : Rp. } 200.000,- \\ \text { Paket Makan } & \text { : Rp. } 600.000,- \\ \text { HTM Wisata } & \text { : Rp. } 300.000,- \\ \text { TOTAL VC } & \text { : Rp. } 1.550 .000,-\end{array}$

Penyelesaian untuk mendapatkan BEP dalam unit maupun rupiah.

\section{Penyelesaian:}

Kapasitas private trip 6 wisatawan

Harga jual private trip Rp. 500.000,- /pack
Total penjualan private trip 6 wisatawan x Rp. 500.000,- = Rp. 3.000.000,-

Biaya variabel pack $=$

Rp. 1.550 .000

6

Rp. 258.000,- / pack

Untuk mencari BEP dalam unit adalah sebagai berikut :

BEP Trip $=$

Rp. 48.000 .000

\section{Rp. $500.000-$ Rp. 258.000}

198 wisatawan

Jadi perusahaan harus menjual trip kepada 198 wisatawan agar BEP.

Kemudian, mencari BEP dalam rupiah adalah sebagai berikut:

BEP Rupiah =

Rp. 48.000 .000

1 Rp. 1.550 .000

Rp. 99.000 .000

Jadi perusahaan harus mendapatkan omset sebesar Rp. 99.000.000,- agar terjadi BEP.

Untuk membuktikan kedua hasil tersebut dengan;

$\mathrm{BEP}=$ Unit BEP $\mathrm{x}$ harga jual unit

$\mathrm{BEP}=198$ wisatawan $\mathrm{x}$ Rp. $500.000=$ Rp. 99.000.000,-.

Setelah mengetahui Break Event Point dari bisnis digital mybaliwisata.com, selanjutnya penulis melakukan analisis Valuasi Bisnis terhadap bisnis digital mybaliwisata.com untuk dapat menilai aspek keuangan mybaliwisata.com lebih dalam. Mybaliwisata.com akan membuat prediksi aspek keuangan selama 5 tahun kedepan, sehingga dapat dihitung seberapa nilai perusahaan mybaliwisata.com saat ini. Berikut tabel mengenai valuasi bisnis mybaliwisata.com sebagai berikut.

TABEL IV

VALUATION BUSINESS MYBALIWISATA.COM

\begin{tabular}{|c|c|c|c|c|c|c|}
\hline \multicolumn{7}{|c|}{ ASPEK KEUANGAN MY BALI WISATA 5 TAHUN KEDEPAN } \\
\hline & & 1 & Thu 2 & Tohu 3 & TThun 4 & TThun 5 \\
\hline Target Wisatawan & & 648 & 702 & 756 & 810 & 864 \\
\hline Pendapatan per pack & $\mathrm{Rp}$ & 500.000 & 500.000 & 500.000 & 500.000 & 500.000 \\
\hline Pendapatan 1 & $\mathrm{Rp}$ & 324.000 .000 & 351.000 .000 & Rp 378.000 .000 & $\begin{array}{ll}\text { Rp } & 405.000 .000 \\
\end{array}$ & Rp 432.000 .000 \\
\hline \multicolumn{7}{|c|}{$\begin{array}{ll}\text { Pendapatan } 1 \text { (wisatawan) } & \text { Kp } \\
\text { Pendapatan } 2 \text { (iklan) } & \\
\end{array}$} \\
\hline Harga Pokok Penjualan & $\mathrm{Rp}$ & 167.184 .000 & 181.116.000 & Rp 195.048 .000 & Rp $\quad 208.980 .000$ & Rp 222.912 .000 \\
\hline Laba Ko & $\mathrm{Rp}$ & 156.816 .000 & 169.884 .000 & $\operatorname{Rp} \quad 182.952 .000$ & $\operatorname{Rp} \quad 196.020 .000$ & $\operatorname{Rp} 209.088 .000$ \\
\hline \multicolumn{7}{|c|}{ 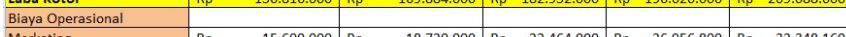 } \\
\hline larketing & $\mathrm{Rp}$ & .000 & .000 & $\mathrm{Rp}$ & 6.800 & 88.160 \\
\hline Sewa & $\mathrm{Rp}$ & 12.000 .000 & 14.400 .000 & $\begin{array}{ll}\mathrm{Rp} & 17.280 .000 \\
\end{array}$ & $\begin{array}{ll}\mathrm{Rp} & 20.736 .000 \\
\end{array}$ & $\begin{array}{ll}\mathrm{Rp} & 24.883 .200 \\
\end{array}$ \\
\hline Internet & $\mathrm{Rp}$ & 6.000 .000 & 7.200 .000 & 8.640 .000 & $\begin{array}{ll}\mathrm{Rp} & 10.368 .000 \\
\end{array}$ & $\begin{array}{ll}\mathrm{Rp} & 12.441 .600 \\
\end{array}$ \\
\hline Transport & Rp & 4.800 .000 & 5.760 .000 & 6.912 .000 & 8.294 .400 & Rp $\quad 9.953 .280$ \\
\hline & $\mathrm{Rp}$ & & 11.520 .000 & Rp 13.824 .000 & $\begin{array}{ll}\mathrm{RP} & 16.588 .800 \\
\end{array}$ & $\begin{array}{ll}\mathrm{Rp} & 19.906 .560 \\
\end{array}$ \\
\hline Bersih & $\mathrm{Rp}$ & 108.816 .000 & 112.284 .000 & \begin{tabular}{|l|l|} 
Rp & 113.832 .000 \\
\end{tabular} & $\begin{array}{ll}R p & 113.076 .000 \\
R\end{array}$ & $\begin{array}{ll}\text { Rp } & 109.555 .200 \\
\end{array}$ \\
\hline sent & & & & & & $\begin{array}{ll}\operatorname{Rp} & 74.561 .428 \\
\end{array}$ \\
\hline aluasi & $\mathrm{Rp}$ & 74.561.428 & & & & \\
\hline
\end{tabular}

Jurnal Zwilling pada tahun 2016 menyebutkan target jumlah wisatawan pertahunnya meningkat $30 \%$ tiap tahun 
berdasarkan rate minimum yang biasanya diterapkan untuk start-up [11]. Harga paket akan kami upayakan dengan konsisten memberi harga setiap tahunnya. Setelah menganalisis menggunakan metode Discounted Cash Flow (DCF), didapatkan nilai perusahaan mybaliwisata.com saat ini yaitu Rp. 74.561.428,-

\section{V.SIMPULAN}

Mybaliwisata.com merupakan sebuah bisnis yang bergerak dibidang travel agent online dimana mybaliwisata.com sebagai penghubung bagi wisatawan dengan desa wisata yang berbasis kemasyarakatan. Dengan Business Model Canvas (BMC), gambaran detail dari keseluruan aktivitas bisnis mybaliwisata.com.

Promosi online yang diterapkan oleh mybaliwisata.com meliputi beberapa media digital seperti; Fanspage Facebook, Instagram Business dan Whatsapp Business. Dengan adanya promosi online dapat mempengaruhi trafik website mybaliwisata.com. Terlihat trafik website mybaliwisata.com yang meningkat terjadi pada bulan Juni 2018 dimana pengunjung pengguna yang unik mencapai 732, jumlah kunjungan mencapai 939, dan jumlah halaman yang dikunjungi sebanyak 3.354 dengan menggunakan Facebook Ads. Hal ini membuktikan bahwa media promosi pada media sosial facebook dapat menarik jangkauan kepada pengunjung, sehingga trafik pengunjung yang melihat halaman mybaliwisata.com mencapai ribuan.

Setelah menganalisis strategi marketing online untuk meningkatkan penjualan travel agent online mybaliwisata.com, selanjutnya menganalisis bagaimana hasil data dari penjualan travel agent online mybaliwisata.com setelah mengimplementasikan strategi marketing online yang dilakukan secara bersamaan selama 5 (lima) bulan tersebut, hasilnya mybaliwisata.com berhasil mendapatkan tamu saat melakukan promosi online di media sosial.

Dari hasil grafik tersebut, penulis dapat melakukan analisis pertumbuhan potensi bisnis yang dimiliki oleh mybaliwsata.com dengan metode BEP (Break Even Point), dimana bisnis digital mybaliwisata.com harus mendapatkan omset sebesar Rp. 99.000.000,- agar terjadi BEP atau perusahaan harus menjual 198 wisatawan agar BEP.

Setelah mengetahui Break Event Point dari bisnis digital mybaliwisata.com, selanjutnya penulis melakukan analisis Valuasi Bisnis terhadap bisnis digital mybaliwisata.com untuk dapat menilai aspek keuangan mybaliwisata.com lebih dalam. Jadi setelah menganalisis menggunakan metode Discounted Cash Flow (DCF), didapatkan nilai perusahaan mybaliwisata.com saat ini yaitu Rp. 74.561.428,--

\section{UCAPAN TERIMA KASIH}

Terimakasih kepada segenap manajemen STMIK Primakara yang telah mensupport hasil riset penulis.

\section{DAFTAR PUSTAKA}

[1] Widiyasari, A., Widagdo, M., Jateng, M., \& Ayun, P. (2015). PENGEMBANGAN WEBSITE MAGAZINE JATENGTRAVELGUIDE.COM (DIVISI REPORTER, DESAINER GRAFIS DAN NEWS EDITOR). Interaksi Online, 13(1). Retrieved from https://ejournal3.undip.ac.id/index.php/interaksionline/article/view/10299

[2] Evariyanti, Fitria Pebri, dkk. 2016. Langitbudaya.com Sebagai Platform Pariwisata Berbasis Kemasyarakatan Bagi Volunteer Mancanegara dan Domestik. Proposal Bisnis KBMI 2016.

[3] Cholid Narbuko, Abu Ahmadi.1997. Metodologi Penelitian. Jakarta: Bumi Aksara

[4] Maulana, G. G., Rispianda, R., \& Amila, K. (2015). Sistem Informasi Pelayanan Jasa Tour Dan Travel Berbasis Website Electronic Commerce (Studi Kasus Ninetours Indonesia). Reka Integra, 3(1).

[5] Elitemarketer, tersedia pada; https://igitalmarketer.id/socialmedia/fitur-bisnis-instagram-akan segera-muncul-untuk-bisnis-anda/, diakses tanggal 4 September 2018

[6] Mutesix, tersedia pada; http://mutesix.com/how-toleveragefacebooks-new-brand-awarenessads/, diakses tanggal 15 April 2018

[7] Kurniawan, E. (2016). Analisis SWOT dan Bisnis Model Kanvas (Studi Kasus Toko EKM Motor). Jurnal Manajemen Dan Bisnis Sriwijaya, 14(2), 277-286

[8] Kurniawan, D. E., Saputra, A., \& Prasetyawan, P. (2018). Perancangan Sistem Terintegrasi pada Aplikasi Siklus Akuntansi dengan Evaluasi Technology Acceptance Model (TAM). Jurnal RESTI (Rekayasa Sistem dan Teknologi Informasi), 2(1), 315-321.

[9] Meyliana, 2011. Analisis Strategi E-marketing Dan Implementasinya Pada Rental Company. Jurnal Ilmiah Jurusan Sistem Informasi, Fakultas IlmuKomputer, Bina Nusantara University: Jakarta Barat.

[10] Ponomban, Christine Praticia, 2013. Analisis Break Event Point Sebagai Alat Perencanaan Laba Pada PT. Tropica Cocoprima. Jurnal EMBA Vol.1 No.4 Desember 2013, Hal. 1250-1261.

[11] Zwilling, Martin C. 2016. Ten Top Techniques for Startup Valuation. Startup Professional, Inc. 